
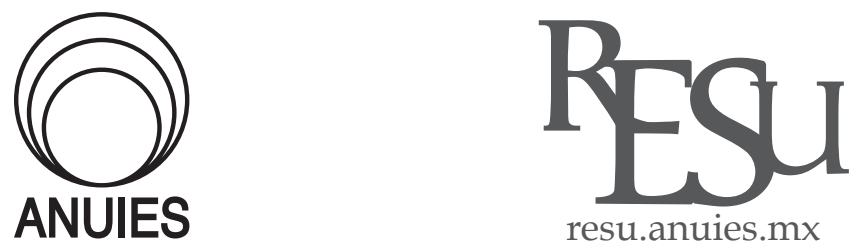

REVITA AE ${ }^{-1}$
EDICACIÓN
SUPERIOR

PESU @

ARTíCULO

\title{
Imaginario occidental y expulsión de las mujeres de la educación superior
}

\section{Occidental imaginary and women's expulsion from higher education}

\author{
Ana Buquet*, Araceli Mingo ${ }^{* *}$ y Hortensia Moreno*** \\ * Centro de Investigaciones y Estudios de Género de la unAM. Ciudad de México, México. Correo electrónico: \\ buquet@unam.mx. \\ ** Instituto de Investigaciones sobre la Universidad y la Educación de la unam. Ciudad de México, México. \\ *** Centro de Investigaciones y Estudios de Género de la unAM. Ciudad de México, México.
}

Recibido el 27 de noviembre de 2017; aceptado el 20 de marzo del 2018.

\section{Resumen}

En este artículo pretendemos establecer una conexión histórica entre la cultura monacal, desarrollada durante el primer milenio de nuestra era, y la formación en los siglos XVII y XVIII de las modernas academias científicas, ambos momentos atravesados por un reclamo de exclusividad varonil que cerró radicalmente para las mujeres el ya de por sí exiguo acceso a las instituciones de creación y de resguardo del saber. Postulamos que la inserción de las mujeres en las universidades y academias actuales sigue siendo conflictiva porque arrastra ese reclamo: la estructura imaginaria del pensamiento en Occidente se construyó sobre la base de la expulsión sistemática de las mujeres, legitimada con argumentos misóginos que persisten en el mundo actual, aunque traducidos en clave moderna como sexismo. Esto explica las resistencias crónicas a su ingreso y su permanencia en las instituciones de educación superior, las cuales se expresan en conductas y actitudes que hemos detectado en investigaciones empíricas. Consideramos que esta reflexión es indispensable si pretendemos superar la discriminación, las exclusiones y el clima de hostilidad contra las estudiantes, académicas y trabajadoras de las universidades.

Palabras clave: Cultura monacal; Misoginia; Sexismo; Educación Superior; Violencia de género 


\begin{abstract}
In this article, we establish a historical connection between the monastic culture developed during the first millennium of our era and the formation of the modern scientific academies in the seventeenth and eighteenth centuries; both were moments marked by demands for male exclusivity, which radically closed off women's already limited access to knowledge institutions. We argue that such demands continue to stymie women's inclusion within universities and academies: the imaginary structure of Western thought was built upon women's systematic expulsion and legitimized by still-prevailing misogynistic arguments, nowadays known as sexism. Such a context explains the ongoing resistance to women's inclusion in higher education institutions, tensions that are expressed through the behavior and attitudes noted in the empirical research. We maintain that this insight is essential if we want to overcome discrimination, exclusion and hostility against women in academe.
\end{abstract}

Keywords: Monastic culture; Misogyny; Sexism; Higher Education; Gender violence

\title{
Introducción
}

$\mathrm{E}^{\mathrm{n}}$ este artículo presentamos algunos ejemplos de la participación de las mujeres en la construcción del conocimiento para reflexionar sobre las instancias que han vuelto escasa o nula su presencia en este ámbito. Nuestra hipótesis de trabajo es que, como lo demuestra la investigación histórica, siempre que la sociedad lo ha permitido, ha habido mujeres que contribuyen a la producción y la diseminación del saber. Su aparente ausencia se explica a partir de mecanismos sociales que se han desarrollado en Occidente para expulsarlas de esta empresa a partir de una división sexual del trabajo que separa las labores corporales de la vida intelectual. Desde tiempos antiguos, en esta repartición de actividades, la responsabilidad por la producción y el cuidado de la vida se considera jerárquicamente inferior en comparación con las tareas especulativas e intelectuales, y se procura producir espacios libres de cualquier interferencia que pudiera interrumpir el puro "demorarse contemplativo" (Han, 2014: 106). La condición imaginaria de esta pureza radica en que el mundo del pensamiento debe estar libre de los compromisos, tentaciones y dificultades que encarnan los cuerpos femeninos.

De este modo, a lo largo del tiempo se han institucionalizado estilos académicos de organización, uno de cuyos referentes imaginarios estriba en el claustro monacal de la Edad Media donde la gente dedicada al trabajo del 
espíritu era una pequeñísima minoría social que podía aislarse del mundo y de las exigencias de la vida material. La investigación histórica revela que la fundación y la puesta en marcha de muchos de estos establecimientos incluyó mujeres, hasta que las autoridades eclesiásticas de los siglos XII y XIII las expulsaron para constituir los espacios que David F. Noble (1993) ha denominado "un mundo sin mujeres". Esta prohibición se actualizó en la instauración de las universidades modernas, que en la mayor parte del mundo mantuvieron cerradas sus puertas para ellas hasta el siglo XIX.

Otro de los estilos organizativos que permiten entender el proceso de expulsión de las mujeres del ámbito científico es la fundación de las academias durante los siglos XVIII y XIX. Como está ampliamente documentado, por una parte, profesiones como la medicina han tenido una importante presencia femenina durante toda la historia de Occidente; por otra parte, durante el arranque de la modernidad, ellas hicieron aportaciones destacadas a los saberes clásicos de las matemáticas, la alquimia, la herbolaria o la filosofía, y participaron en la fundación de disciplinas nacientes como la astronomía, la entomología, la botánica o la geología. Antes de la profesionalización de las viejas y nuevas especialidades, la participación epistemológica y práctica en el desarrollo del saber no requería la ostentación de credenciales; la mayoría de los hombres y mujeres que lideraron la revolución científica eran amateurs y diletantes que aprovechaban sus pequeños talleres productivos para instalar laboratorios improvisados, o armaban sus propios instrumentos ópticos en las azoteas de sus viviendas, o emprendían expediciones de descubrimiento por tierras ignotas. Todo por cuenta propia, sin la subvención de instituciones académicas y con la libertad suficiente para permitir que hermanas, hijas, esposas y madres estuvieran presentes en el proceso de trabajo de esas empresas, o que las viudas y huérfanas prosiguieran con los esfuerzos familiares.

En este contexto, la profesionalización de las disciplinas y la institución de las primeras academias científicas se dio a la par con la expulsión explícita y flagrante de las mujeres que habían figurado tanto en la profesión médica como en el establecimiento de las ciencias modernas. Esta proscripción se legitimó mediante un discurso sexista - continuador de la lógica del claustro medieval y de la misoginia imperante en épocas anteriores - que legitimaba la separación de espacios, ahora basado en un paradigma naturalista. De esta manera, lo que en la Antigüedad y en la Edad Media había sido una posibilidad para una mínima élite de mujeres, en la modernidad se convirtió en una imposibilidad generalizada que declaraba al conjunto del sexo femenino incapacitado para el saber. Así se difundió un imaginario cada vez más sofisticado donde se atribuía a las mujeres un papel primero marginal y luego 
por completo ausente de la vida intelectual, para recluirlas imaginariamente en el espacio doméstico, como si esto fuese natural y eterno.

Para consolidar esta expulsión del ámbito académico, universitario y científico, muchas de las aportaciones femeninas al conocimiento fueron sistemáticamente borradas de los registros históricos y han requerido de un minucioso trabajo de reconstrucción. No debemos descartar que exista una voluntad maliciosa de suprimir cualquier evidencia que muestre la aptitud femenina para el campo intelectual; pero, sobre todo, se ha predispuesto la incredulidad del historiador que se encuentra con pruebas de su desempeño. Alic (1991) reseña este proceso en muchos casos en que se ha negado a las mujeres la autoría de sus propias obras y éstas se han atribuido erróneamente a varones - sus confesores, hermanos, padres, maridos o amantes - o se ha puesto el acento en las biografías sociales o sexuales de aquellas que demostraron una genialidad incompatible con este imaginario. El resultado de tal panorama permea las épocas. El sentido común del mundo actual postularía que las mujeres, por razones naturales, nunca han tenido y nunca contarán con la habilidad mental necesaria para dedicarse a las tareas del espíritu.

En el primer apartado, exponemos el argumento de la expulsión femenina del ámbito del saber con una breve reseña histórica donde recuperamos investigaciones que han mostrado su innegable relevancia para las instituciones monacales del primer milenio de nuestra era y para la revolución científica durante la modernidad, así como los procesos culturales y sociales que dieron lugar a su marginación, su expulsión y su exclusión.

En el segundo apartado, abordamos un caso que ejemplifica cómo opera este sentido común: se trata del chiste que hizo Timothy Hunt en 2015 sobre la presencia de chicas en los laboratorios. En clara discordancia con la tradición escolástica de las universidades y la cerrazón de las academias, las mujeres meten el cuerpo - y con el cuerpo, el sexo, el desorden, el ruido, la confusión - al espacio sagrado de la producción del saber. La idea de que las mujeres están "fuera de lugar" cuando ingresan en la academia ha impactado no sólo el dominio de las denominadas "ciencias duras" o sTEM (ciencia, tecnología, ingenierías y matemáticas, por sus siglas en inglés), sino inclusive el campo de las humanidades y las artes, por ejemplo, con la sustracción de los registros históricos de la producción artística y filosófica de las mujeres. El caso de Tim Hunt es particularmente interesante por la respuesta que generó entre las científicas que se sintieron interpeladas.

En el tercer apartado, sostenemos que la cultura de la exclusividad varonil en los ámbitos de producción y de diseminación del conocimiento se traduce, en el siglo xxI, en un sexismo persistente que funciona como tendencia expulsora de las mujeres. Ilustramos la forma como se reproduce el sexismo 
en los ambientes universitarios y académicos mediante la presentación de resultados empíricos de una investigación en curso sobre el sexismo en la Universidad Nacional Autónoma de México.

\section{¿Exclusión o expulsión?}

Si bien las mujeres han participado en la empresa occidental de producción y de transmisión del saber desde la Antigüedad, su presencia en este ámbito ha sido desde siempre conflictiva. No obstante, hay evidencia suficiente en la investigación histórica para demostrar la importancia de esta participación en varios momentos decisivos (véase, por ejemplo, Alic, 1991; Sánchez Mora, 2004; Schiebinger, 2004; Noble, 1993; Brown, 1988; Commo McLaughlin, 1974; Épiney-Burgard y Zum Brunn, 1998; Palermo, 2006), así como también puede corroborarse que existe una tendencia persistente a expulsarlas de este coto que se reivindica como fundamentalmente masculino. De esta forma, por ejemplo, encontramos largas épocas de actividad femenina floreciente en dominios como la medicina, que terminaron con la proscripción de las médicas y de las parteras mediante diversas estrategias; así, "mujeres que en el siglo XIII eran llamadas médicas fueron consideradas charlatanas y brujas en los siglos XIV y XV" (Alic, 1991: 73).

Esta circunstancia arroja una importante pregunta sobre la entrada de las mujeres al mundo de la educación superior a partir del siglo XIX. Desde el sentido común puede afirmarse que se trata de una presencia completamente nueva, lo cual explicaría las profundas resistencias que encontraron las pioneras en el mundo de la ciencia, las humanidades y las artes cuando se enfrentaron por primera vez a la posibilidad de estudiar o de ejercer una profesión. El discurso sexista, con que se articulan tales resistencias, podría atribuirse a la continuidad que el pensamiento moderno establece con los órdenes tradicionales en la construcción de las imágenes sobre lo que se considera adecuado para los hombres y mujeres.

En este trabajo ponemos en duda esta supuesta novedad y proponemos que el discurso de la modernidad aporta precisamente una ruptura al postular la ineptitud natural de las mujeres para el campo intelectual. Thomas Laqueur (1994) ha explicado cómo la formación de la disciplina anatómica de los siglos XVII y XVIII parece guiarse por un objetivo principal: la demostración empírica de que los cuerpos de hombres y mujeres son inconmensurablemente diferentes. Esta tendencia se opone de manera frontal al conocimiento antiguo, que había considerado diferentes aspectos de la corporalidad humana - entre ellos, los órganos genitales, pero también el esqueleto y el sistema 
nervioso - comunes a los dos sexos. De esta forma, el cuerpo "natural" se convierte en el campo de batalla en la redefinición de las relaciones sociales entre mujeres y hombres:

Las promesas de la Revolución francesa [...] dieron lugar no sólo a un nuevo feminismo auténtico, sino también a un nuevo tipo de antifeminismo, un miedo nuevo a las mujeres, y también a las fronteras políticas que engendraban barreras sexuales en la pareja. La creación de una esfera pública burguesa [...] agudizó la cuestión de qué sexo(s) debería formar parte del discurso. Es evidente que quienes se oponían al aumento del poder civil y privado de las mujeres - la gran mayoría de los hombres que se dejaban oír - aportaron pruebas de la inadecuación física y mental de las mujeres para tales progresos: sus cuerpos las hacían ineptas para los espacios quiméricos que la revolución había abierto sin reparar en las consecuencias (Laqueur, 1994: 331).

Las tensiones, que se generan entre el postulado igualitario de la Ilustración y su traducción efectiva en prácticas discriminatorias, conducen a una larga polémica sobre la educación femenina mediante la cual se define su lugar en el mundo social; al situarlas en el espacio doméstico, el discurso de la modernidad postulaba que las mujeres habían estado fuera de las instituciones de producción del saber desde su aparición más antigua. En este trabajo sostenemos que, en contradicción con esa idea, existe suficiente evidencia para demostrar que la construcción del conocimiento, tal y como lo conocemos en Occidente, tuvo en su origen un impulso femenil decisivo.

Por ejemplo, en la Italia medieval, las escuelas mixtas eran frecuentes (Alic, 1991: 74). Ya en los siglos XV y XVI, las nobles italianas recibieron educación y se refinaron en las cortes junto con los varones. Pero anteriormente, en las universidades de Bolonia, de Padua, de Nápoles y de Salerno seguían cursos que las habilitaban para ejercer la medicina; también había mujeres (como Constanza Calenda) que impartían cátedra en las universidades. Sólo así tiene sentido un decreto como el que se emitió en 1377 prohibiendo su entrada a la Universidad de Bolonia; es decir, no tendría sentido prohibir algo que no estaba ocurriendo:

Ya que la mujer es la razón primera del pecado, el arma del demonio, la causa de la expulsión del hombre del paraíso y de la destrucción de la antigua ley, y ya que en consecuencia hay que evitar todo comercio con ella, defendemos y prohibimos expresamente que cualquiera se permita introducir a una mujer, cualquiera que ella sea, aunque sea la más honesta, en esta universidad (Decreto de 1377 de la Universidad de Bolonia, citado en Palermo, 2006: 12). 
Margaret Alic reseña un extendido movimiento de rebelión y protesta de los varones en las universidades de la época para suprimir la competencia que les representaban las mujeres (Alic, 1991: 73). Esta supresión requiere contextualizarse con un largo desarrollo anterior que nos permite asomarnos al origen de los principales centros de producción y de conservación del saber durante el primer milenio de nuestra era, es decir, los monasterios y abadías que acogieron a quienes se dedicaron durante la Edad Media a la lectura, la transcripción, la traducción y la escritura de los textos más importantes del canon de la época. Aunque esta historia está velada por múltiples factores, resulta importante saber que muchos de estos establecimientos admitieron, en sus inicios, la participación femenina a partir de lo que se ha denominado "el ideal de la androginia", el cual postulaba una forma de igualdad entre mujeres y hombres, aunque sólo en el plano espiritual (véase Brown, 1988; Noble, 1993).

No se trata de un principio de igualdad universal y abstracto, como el que postula la modernidad, sino de un principio filosófico-religioso: las almas no tienen sexo y, por lo tanto, hombres y mujeres son iguales ante los ojos de dios. Esta circunstancia sólo se cumple después de la muerte, a condición de evitar la concupiscencia (Tazi, 1989: 527). No obstante, el ideal permitió que algunas mujeres pertenecientes a la aristocracia y en condiciones sociales muy peculiares - por ejemplo, no estaban casadas o eran viudas y herederas de pequeñas fortunas - se dedicaran a la vida contemplativa en los ambientes aislados de los claustros (Brown, 1988). Como es bien sabido, los claustros religiosos de Europa en la Edad Media se encargaron de preservar, de traducir y de continuar la tradición escrita de la cultura occidental. David F. Noble (1993) estudió la importante participación femenina en esta empresa y, sobre todo, abordó la formación de la ortodoxia que inventó la herejía y la identificó con las mujeres, con lo cual propició el surgimiento de un mundo sin mujeres: "una sociedad compuesta exclusivamente por hombres, forjada para escapar de las mujeres, y con el propósito de rehacer el mundo a imagen y semejanza de la mitad de la humanidad" (Noble, 1993: 108).

Pero antes de que esta ortodoxia se estableciera y el cristianismo se convirtiera en una religión de Estado, se abrió una ventana de oportunidad que permitió a ciertas viudas de la aristocracia alcanzar un control significativo sobre sus propiedades y concedió a sus hijas disfrutar de una vida independiente. Algunas de las integrantes de este grupo privilegiado de la sociedad - el único que poseía los medios económicos para impulsar la naciente empresa salvífica - abrazaron la vida monacal tal y como se llevaba a cabo en los primeros siglos del cristianismo, es decir, como un alejamiento del mundo y una dedicación a la vida del espíritu. 
Hay abundante evidencia histórica de la presencia femenina en los monasterios y abadías a lo largo de todo el mundo cristiano desde el siglo III hasta el siglo XII. La función de estos establecimientos en la preservación del pensamiento clásico y en la producción teológica y literaria de la Edad Media es indiscutible, como también lo es el liderazgo de muchas mujeres como abadesas, teólogas y poetas a la par de sus compañeros de vocación, con quienes en general se abstenían de relaciones carnales y mantenían una hermandad espiritual (Épiney-Burgard y Zum Brunn, 1998; Brown, 1988; Commo McLaughlin, 1974).

La actividad intelectual durante la época está limitada a estos reducidísimos espacios donde una muy restringida fracción de la sociedad tenía acceso al conocimiento de la escritura, mientras que la enorme mayoría de la población se dedicaba durante toda su vida al trabajo agrícola en condiciones de servidumbre, y las élites económicas, militares y eclesiásticas mantenían el orden social mediante la fuerza de las armas.

De manera paralela con la cultura monástica, durante el periodo estudiado por Noble (1993), se desarrolla una cultura clerical-burocrática ligada a los centros de poder y que terminará por imponerse desde el papado en Roma. Aunque hay una importante relación entre la cultura monacal y la clerical - de modo que prácticamente todos los hombres destacados en la política de la iglesia medieval proceden de monasterios - , las diferencias entre los dos espacios son contrastantes, por ejemplo, muchos de los sacerdotes - integrantes de la cultura clerical - estaban casados y tenían descendencia legítima, mientras que en la cultura del monasterio, donde los monjes no tenían la obligación de ordenarse como sacerdotes, se practicaban votos de castidad, de pobreza, de obediencia y de silencio.

Al final, la iglesia latina evoluciona en una fusión entre la cultura ascética y la cultura burocrático-política, de modo que se implanta el celibato como obligatorio para todos los integrantes de la institución eclesiástica, al tiempo que se sanciona la pertenencia a la jerarquía como un privilegio exclusivamente varonil. Según Noble, es aquí - en la lucha del clero latino por imponerse como la mediación entre dios y la humanidad - donde tomó forma esa curiosa cultura que da cuenta de uno de los varios orígenes de la ciencia occidental:

Arraigada en el monacato masculino del siglo iv y con el sello distintivo de su énfasis sobre el celibato total del clero, la cultura clerical de la jerarquía de la iglesia latina se había convertido hacia la Alta Edad Media en la cultura del sacerdocio, así como en la cultura del saber. Pero la consolidación de esta cultura clerical ascética requirió un milenio de lucha e incluso, después de eso, la lucha nunca cesó realmente. Una vez afianzados, los defen- 
sores de la ortodoxia han tenido que lidiar con resurgimientos periódicos de la heterodoxia anticlerical, que cada vez vuelve a abrir espacios para las mujeres. El destino de las mujeres en el mundo occidental del pensamiento estaba entonces ligado a la tensión recurrente entre la ortodoxia y la heterodoxia que marcó toda la historia del occidente cristiano (Noble, 1993: 123).

La aparición de las modernas universidades abarca precisamente los siglos durante los cuales las mujeres son expulsadas de toda institución dedicada al pensamiento. De haber sido recintos de formación intelectual y de creación filosófica y literaria, las órdenes religiosas femeniles se convierten, por decreto papal, en organizaciones dedicadas a labores de servicio, completamente sujetas a la autoridad varonil e imposibilitadas de acceder a ninguna posición jerárquica ni en el ámbito cotidiano ni en las altas esferas políticas del clero. El factor práctico de esta exclusión es la prohibición a las mujeres de ejercer el sacerdocio. Los ámbitos religiosos donde se cultiva la vida espiritual y donde se origina el canon se vuelven espacios exclusivamente masculinos. Esta exclusividad signará la formación de las universidades modernas que se mantendrán cerradas a las mujeres en la mayor parte del mundo occidental durante muchos siglos.

Como lo han mostrado Margaret Alic (1991), David F. Noble (1993) y Londa Schiebinger (2004), a lo largo de la mayor parte de su evolución, la cultura de la ciencia no simplemente ha rechazado a las mujeres, sino que ha sido definida en oposición a ellas y en su ausencia; de esa forma, el mundo de la ciencia ha permanecido como un lugar ajeno a las mujeres.

El siguiente momento decisivo del proceso de expulsión de las mujeres del ámbito intelectual es la revolución científica. Se trata de un largo desarrollo que tiene lugar en diferentes espacios de la vida social. Schiebinger (2004) documenta la presencia femenina en momentos clave de ese desarrollo: además de los monasterios medievales, describe los espacios donde hubo condiciones materiales que posibilitaron el acceso al saber de algunas de ellas, ya fuera por su pertenencia a las élites o por su relación con los procesos de trabajo. Tales espacios incluyen las cortes del Renacimiento, los salones de la Francia pre-revolucionaria, el mundo artesanal, la partería, la cocina y las empresas familiares pioneras de la astronomía, la botánica y la taxonomía.

Estos momentos son los antecedentes de lo que ocurriría en los siglos XVII y XVIII, durante los cuales la participación en la empresa de descubrimiento, de experimentación y de especulación que dieron lugar a la ciencia moderna estaba abierta a ciertos sectores sociales y no establecía una distinción rígida 
con base en el sexo de la persona que la profesaba. Esto permitió que algunas mujeres cultivaran las ciencias experimentales, la historia y la filosofía naturales:

Puede resultar sorprendente que, entre 1650 y 1710, una importante proporción -aproximadamente un $14 \%$ - de todos los astrónomos alemanes fueran mujeres. Esas mujeres no procedían de la aristocracia, sino del prosaico mundo del taller artesanal, en el que había tanto mujeres como hombres trabajando en los negocios familiares. Las tradiciones artesanales, fundamentales para la vida laboral de la Europa moderna temprana, contribuyeron asimismo al desarrollo de la ciencia moderna (Schiebinger, 2004).

Los talleres familiares, donde se llevaba a cabo el trabajo de producción artesanal dominante en las ciudades del medioevo, contaban con la actividad creativa de las hijas y de las esposas de los dueños, además de las mujeres que entraban en calidad de aprendices, o las que fundaron sus propios locales o que los heredaron de sus maridos. En muchas de estas factorías se realizaba lo que más adelante sería considerado como producción científica, con la intervención de aquellas que ya laboraban ahí (Schiebinger, 2004, pp. 105106). Al igual que muchos varones pioneros de la investigación científica, las mujeres encontraron en las tradiciones artesanales acceso a las herramientas de la ciencia, ese proyecto completamente nuevo que aún se desenvolvía por fuera de las instituciones.

Fue la institucionalización del proyecto científico la que instauró las regulaciones a partir de las cuales se expulsó a las primeras científicas de los espacios académicos y universitarios. Londa Schiebinger (2004) aporta un ejemplo decisivo de este proceso en su reseña de la exclusión sistemática de que fueron objeto las parteras cuando sus prácticas se convirtieron en una profesión que requería no solo entrenamiento escolar - en oposición al aprendizaje empírico - , sino sobre todo una certificación que autorizaba para ejercer la profesión de manera exclusiva a quienes habían pasado por las universidades, que ya eran espacios de privilegio masculino. Es así como la ciencia y la tecnología del parto, diligencias que habían sido desarrolladas y cultivadas "exclusivamente por comadronas al menos durante dos mil años" (Schiebinger, 2004, p. 157), se transformaron en un enclave masculino.

Como bien lo señala esta autora, la formación de los primeros científicos - el término incluye a las mujeres - no dependía de las universidades, sino de la práctica directa y del intercambio de ideas, los cuales ocurrieron en talleres, salones, observatorios y laboratorios caseros, y en diferentes usos de la atención médica; pero el impulso determinante de la investigación científica 
radicó en la conformación de instituciones formales: por un lado, las academias, por otro, la aparición de las profesiones. Ambas instancias funcionaron como mecanismos decisivos para la exclusión femenina. Lo paradójico es que, en el momento de fundación de las academias de ciencias a lo largo y ancho de Europa, había una cantidad importante de mujeres que hubieran pertenecido por mérito propio a estos organismos $-\mathrm{y}$ habrían entonces disfrutado de los emolumentos que tales instituciones aportaban -, pero que no fueron admitidas por el hecho de ser mujeres. Por ejemplo, Maria Winkelmann no ingresó a la Academia de Ciencias de Berlín a causa de argumentos como el siguiente:

Debe usted ser consciente de que la decisión que pronto habrá de tomar podría ser tomada como precedente. En principio somos de la opinión de que este caso debe ser juzgado no solamente por sus presentes méritos sino también como pudiera serlo en adelante, pues lo que le concedamos a ella podría servir de ejemplo para el futuro (carta de Jablonski a Leibniz 1710, citado en Schiebinger, 2004: 140).

Es decir, el origen de la ciencia, como momento cardinal de la modernidad, atestigua la participación de una importante cantidad de mujeres que debieron ser activamente expulsadas o marginadas a partir de la aplicación de las políticas de institucionalización de las academias y de las profesiones.

\section{“Déjenme que les cuente sobre mis problemas con las chicas" (Hunt, 2015)}

El resultado a largo plazo de la expulsión femenina del mundo académico y científico se deja sentir en el siglo XxI en diversas expresiones de sexismo y de discriminación. Una muestra muy visible del sentimiento generalizado respecto de las condiciones de posibilidad de la producción científica puede apreciarse en el caso que reseñamos a continuación. A sus 72 años, el doctor Richard Timothy Hunt - premio Nobel de Medicina en 2001 (junto con Paul Nurse y Leland H. Hartwell) por su descubrimiento de las moléculas de proteínas que controlan la división de las células - disfrutaba del prestigio y el reconocimiento públicos del mayor logro que se puede obtener en la carrera científica y en la escala social. Además de ganador del Nobel, era integrante del Instituto Británico de Investigaciones sobre Cáncer, profesor en la Universidad de Londres y miembro de la Royal Society of London for Improving Natural Knowledge (academia de ciencias fundada en el siglo XVII en 
Inglaterra). Para su desdicha, el 9 de junio de 2015, en Seúl, en la Conferencia Internacional de Mujeres Periodistas de la Ciencia, se le ocurrió soltar al aire el siguiente comentario:

Es raro que a un monstruo chovinista como yo se le pida que se dirija a las científicas. Déjenme que les cuente sobre mis problemas con las chicas. Ocurren tres cosas cuando están en el laboratorio: te enamoras de ellas, ellas se enamoran de ti y, si las criticas, lloran. ¿Quizá deberíamos hacer laboratorios separados para muchachos y muchachas? A ver, en serio, estoy impresionado por el desarrollo económico de Corea. Y las científicas desempeñaron, sin duda, un papel importante en él. La ciencia necesita a las mujeres, y las mujeres deben dedicarse a la ciencia, a pesar de todos los obstáculos, y a pesar de los monstruos como yo (The Royal Society, 2015). ${ }^{1}$

Alguien entre las asistentes twitteó su descontento ante tal declaración, que se volvió viral; aunque, de manera por demás intrigante, no se reprodujo el discurso completo, sino solamente el punch line: cuando las mujeres están en el laboratorio "te enamoras de ellas, ellas se enamoran de ti y, si las criticas, lloran". Las respuestas públicas no se hicieron esperar. La Royal Society se distanció ese mismo día de los comentarios de Sir Tim Hunt FRs: ${ }^{2}$

La Royal Society cree que, para lograr todo lo que puede, la ciencia necesita hacer el mejor uso de las capacidades de investigación de toda la población. Demasiados individuos talentosos no realizan su potencial científico a causa de problemas tales como el género, y la Royal Society está comprometida en ayudar a que esto se enderece. Sir Tim Hunt estaba hablando de manera individual y sus comentarios no reflejan de ninguna manera el punto de vista de la Royal Society (The Royal Society, 2015).

Pero la reacción más severa fue la de la Universidad de Londres, que exigió la renuncia de Hunt a su puesto honorario - dado que el profesor ya está retirado - con el argumento de que sus opiniones dañaban la reputación de tan honorable organismo. Desde luego, también se ha levantado un importante sector en defensa del profesor. Varias académicas - la física Athene Donald, la bióloga Ottoline Leyser y la fisióloga Nancy Rothwell - se manifestaron a su favor con el argumento de que él ha apoyado a muchas jóvenes científicas. Rothwell afirma: “Muchas de ellas darán testimonio de la enorme ayuda y estímulo que le da Tim a los jóvenes científicos, tanto hombres como mujeres. De hecho, ha entrenado y orientado a algunas científicas fenomena-

\footnotetext{
${ }^{1}$ Todas las traducciones son de las autoras.

${ }^{2}$ Las siglas FRS significan que Hunt pertenece a la Royal Society.
} 
les" (McKie, 2015). Por su parte, el comunicador Jonathan Dimbley renunció a su puesto honorario en la Universidad de Londres - e invitó públicamente a otros profesores a sumarse a la protesta - para condenar lo que considera un castigo desmesurado. A raíz del problema, Dimbley declaró: "esta universidad tiene una larga y honorable tradición en la defensa de la libertad de expresión, sin importar lo objetable que ésta [la expresión] sea. Sir Tim hizo un chiste muy malo y recibió la respuesta correcta. Pero ya se disculpó" (Meikle, 2015).

Más allá de la reflexión acerca del poder sobre la vida de las personas ejercido en este momento por las redes sociales, conviene pensar en los contenidos de las declaraciones de este profesor - cuya esposa, la también científica Mary Collins, se declara feminista y considera que el desenlace de esta anécdota ha sido tremendamente injusto con su marido-, porque la ignominia parece haber dejado en suspenso la discusión que sugieren tales opiniones respecto de la participación femenina en la vida académica. Convendría cuestionar si la réplica acelerada tanto de la opinión pública como de las autoridades académicas es sólo un posicionamiento de rectitud política que, como cortina de humo, invisibiliza y acalla precisamente aquello que pretende reivindicar. De esta forma, el linchamiento del chivo expiatorio limpia el prestigio de las instituciones que se reafirman en su prístina probidad: “¡nosotros no somos sexistas!”.

Convendría también, desde nuestro punto de vista, poner sobre la mesa los temas implícitos y explícitos en los comentarios de Hunt, antes de descalificar de manera terminante cualquier intervención que se atreva a señalar problemas derivados de la presencia de mujeres en las universidades. Porque la inserción de las mujeres en la academia es, en efecto, problemática.

Uno de los resultados más interesantes del incidente es la serie de fotografías y comentarios que desató en Twitter el hashtag \#distractinglysexy, donde una considerable cantidad de científicas que trabajan en laboratorios se mofan con enorme eficacia de la alusión de Hunt a la inquietante propensión femenina al enamoramiento y a las lágrimas (Twitter, s/f). Algunas de las ingeniosas investigadoras dicen cosas tales como:

Puf, ¡logré atravesar esta disección de tejido cerebral sin enamorarme ni llorar!

[Sonja Vernes]

Lágrimas, risas, romance, sucia, sucia flotación, ¡la \#archaeology me excita tanto ahora mismo!

[Lorna Richardson] 
Nada como un tubo de ensayo lleno de excremento de chita como para volverte \#distractinglysexy

[Sarah Durant]

El problema con las biólogas marinas es que no nos podemos concentrar cuando estamos húmedas

[Sarah Seston]

En las fotos, las investigadoras aparecen en entornos de trabajo nada sugestivos (desde el punto de vista sensual), portando máscaras y guantes enormes o embutidas en escafandras y aparatosos equipos de protección que las cubren de pies a cabeza. O simplemente hacen alusión a la total falta de sex appeal de labores cotidianas tales como recabar muestras, mirar por un microscopio, lidiar con animales enjaulados, excavar en un sitio arqueológico o manejar sustancias peligrosas. Youtube publicó un video con algunas de las fotografías y comentarios (Youtube, s/f).

Es decir, una de las consecuencias de los comentarios del profesor es la visibilización de una intensa actividad súper especializada, altamente tecnologizada y no exenta de riesgos, poblada por un número impresionante de mujeres. Los laboratorios del mundo se benefician de esta fuerza de trabajo eficiente y productiva, de esta masa de egresadas de las universidades que se han integrado a la empresa científica con mayor o menor éxito individual, pero sin duda, para el enorme éxito de las instituciones.

El segundo punto a destacar es precisamente la medida de ese éxito. Ya bien entrado el siglo XXI, tenemos cifras que permiten calibrar la integración de las mujeres a la ciencia. Para el Reino Unido, las más recientes estadísticas sobre la presencia femenina en ciencia, tecnología, ingenierías y matemáticas muestran que ellas están entrando en la fuerza de trabajo a mayor velocidad que los hombres; sin embargo, su proporción en la industria todavía es significativamente menor. El análisis de la campaña WISE, que promueve la participación femenil en la ciencia, revela que el número de mujeres que trabajan en ocupaciones científicas se ha incrementado a 52000 en dos años, pero hace falta que se contrate a otro millón de mujeres para lograr que la fuerza de trabajo femenil llegue apenas a 30\% del total, lo cual sería un logro histórico (WISE, 2015).

La situación de las mujeres en la academia - científica o humanística - y en el mundo tecnológico no es mejor en otros países; más bien, tiende a ser peor. No es sólo que haya una proporción ínfima de mujeres contratadas en las industrias y en las ramas relacionadas con las denominadas "ciencias duras" - por lo general en puestos subordinados y con una brecha salarial importante - sino que, además, las matrículas en las universidades muestran una tendencia global: aunque año con año se inscriben más y más mujeres en 
programas académicos, todavía están lejos de acercarse al 50\% que equilibraría una participación igualitaria en el mundo del trabajo, por ejemplo, dentro de las propias instituciones universitarias y académicas.

Las especulaciones acerca de esta disparidad han encontrado diferentes formas de explicarla. Entre las más populares y conocidas persiste el todavía discutido mito de la inferioridad intelectual femenil, que se ha ido aderezando con argumentos más o menos esencialistas. Los planteamientos con que se descalifica la participación femenina en academias y universidades repiten conjeturas acerca de las diferencias sexuales biológicas para derivar en la consecuencia social de que "las mujeres no están hechas para las actividades creativas e intelectuales".

Ahora bien, el argumento de la existencia de diferencias biológicas responsables de un desempeño diferencial de las mujeres ha sido rebatido sistemáticamente por investigaciones serias (véase, por ejemplo, Caplan, Crawford, Hyde y Richardson, 1997; Fausto-Sterling, 1992; Schiebinger, 2004; Fine, 2010). Los resultados de estas investigaciones indican que la inserción problemática de las mujeres en la vida académica y científica requiere de enfoques que ya no se centren en las diferencias - culturales o biológicas, esenciales o construidas - entre machos y hembras de la especie, o entre mujeres y hombres, o entre la feminidad y la masculinidad, sino más bien en las condiciones sociales y culturales en que se ha dado esta inserción.

\section{¿Qué detona la presencia de mujeres en los espacios universitarios?}

A continuación, queremos ilustrar algunas estrategias colectivas e individuales con las que los varones enfrentan la incorporación femenina a las instituciones de educación superior. Englobamos esas estrategias con el concepto de sexismo. Desde nuestro punto de vista, el sexismo se construye en una relación de continuidad y de ruptura con la misoginia. Según la RAE, la misoginia se define como aversión u odio hacia las mujeres (RAE) y consiste en una tendencia sostenida en diferentes culturas cuyo principal efecto es el emplazamiento práctico y simbólico de las mujeres en un lugar de subordinación social (Bosch et al., 1999). La misoginia apuntala los discursos sobre el lugar de las mujeres en la vida humana (Holland, 2010). La misoginia y el sexismo recogen temas delineados en las más diversas expresiones culturales (mitología, religión, literatura, artes escénicas, artes visuales, etcétera) y en el sentido práctico, en los contactos inmediatos que se establecen entre las personas en la vida diaria. 
En el mundo moderno, el sexismo no es un hecho aislado ni excepcional, sino una práctica rutinaria, dirigida y llena de sentido social. Se trata de percepciones y de prácticas de sentido común - apuntaladas en la certidumbre de una distinción natural entre mujeres y hombres - que establecen lugares jerárquicos entre los sexos y postulan un posicionamiento de supremacía varonil. Desde nuestra perspectiva teórica, el sexismo es performativo: se realiza en la acción; es en la vida cotidiana, en la enmarañada red de las interacciones sociales, donde se manifiesta, se consuma y se reproduce (Mingo y Moreno, 2017). La principal diferencia entre sexismo y misoginia reside en la inscripción del primero en el registro del pensamiento racionalista de la modernidad, en oposición al pensamiento mítico-religioso del orden simbólico tradicional. Lo paradójico es que el sexismo es un pensamiento reaccionario, es decir, se trata de una tendencia tradicionalista, pero a la vez se presenta como un pensamiento positivista que rompe con el misticismo y la superstición.

El concepto de sexismo tiene la utilidad de que nos permite detectar cómo operan las estrategias expulsoras de las mujeres en los espacios universitarios. El contexto de nuestra investigación es la Universidad Nacional Autónoma de México (UNAM), donde llevamos más de diez años trabajando sobre violencia, discriminación y segregación por razones de género.

La UNAM es una de las universidades más grandes e importantes de América Latina; su historia moderna se remonta a 1910, pero algunos la consideran como la continuación de la Real y Pontificia Universidad de México que se fundó en el siglo XVI. Su propósito primordial es "estar al servicio del país y de la humanidad, formar profesionistas útiles a la sociedad, organizar y realizar investigaciones, principalmente acerca de las condiciones y problemas nacionales, y extender con la mayor amplitud posible, los beneficios de la cultura" (UNAM, s/d). Actualmente cuenta con una población estudiantil integrada por 349539 estudiantes (205 648 de licenciatura, 112624 de bachillerato, 30363 de posgrado y 904 en el propedéutico de la Facultad de Música), de los cuales, $50.9 \%$ son mujeres y $49.1 \%$, hombres. Su planta académica aparece formada por 40184 especialistas (44.3\% mujeres y 55.7\% hombres) (UNAM, 2017). Ofrece 122 carreras a nivel licenciatura y cuenta con 31 sedes académicas ubicadas en la Ciudad de México y en distintos estados del país. Es pertinente señalar que si bien hoy día se observa un equilibrio en la matrícula por sexo, éste se logró apenas en el año 2000, pues por largo tiempo el número de estudiantes mujeres era claramente inferior al de los varones. Es decir, se trata de una universidad cuya historia nos muestra las marcas de las convenciones de género a las que las mujeres han debido hacer frente para lograr su ingreso. 
Las modalidades que adopta el sexismo en la comunidad de la UNAM son múltiples y transitan desde formas encubiertas, poco claras, sutiles, hasta aquellas en que la violencia se expresa sin velo alguno. En las primeras, el problema queda oscurecido por la aparente insignificancia de ciertos mensajes que se expresan, por ejemplo, en bromas, omisiones, tonos de voz, consideraciones no pedidas o instancias del lenguaje corporal que traducen la tenacidad de añejas creencias sobre la carencia de valor y las capacidades deficientes de las mujeres, consideradas como un colectivo indiscernible. Los contenidos de estos actos, muchas veces irreflexivos, están arraigados en los libretos de género que los sujetos interiorizan a lo largo de su vida de manera acrítica.

Desde luego, una fracción importante de tales actitudes podría ignorarse como si fuera un aspecto molesto pero irrelevante de las relaciones entre los sexos. Sin embargo, los testimonios que hemos reunido como integrantes del grupo de investigación "Género y Educación Superior", donde hemos realizado diversas investigaciones sobre el tema a lo largo de más de 10 años, nos permiten afirmar que el sexismo es un componente tóxico de las relaciones sociales y tiene consecuencias cuya gravedad, aunque es difícil de medir, se materializa día a día en la experiencia de las mujeres como una lacra que no sólo lesiona su autoestima, sino que produce verdaderos obstáculos para una elemental calidad de vida. Un buen ejemplo de esto aparece en el relato que hace una joven profesionista para describir la forma en que su jefe la acosaba sexualmente:

No sé cómo nombrarlo, una sensación, un sentimiento que va más allá de lo cognitivo, algo muy sutil que mina la confianza en una misma. Lo que antes narré son hechos contundentes y evidentes; sin embargo, hay otros gestos, tonos, miradas, posturas que intimidan y agreden, y son tan resbaladizos que no se pueden sujetar para mostrarlos a alguien y decir: “¡mira!” (citada en Mingo y Moreno, 2015: 147).

Ciertos sucesos, ocurridos en fechas recientes en la UNAM, más la información que ofrecen varias investigaciones realizadas en esta institución, nos permiten apreciar la forma en que se expresan y actualizan creencias, prejuicios, posicionamientos y estereotipos acerca de las mujeres. La tolerancia social ante este tipo de percepciones, de disposiciones y de acciones forma parte del habitus universitario y es muy difícil de combatir; hacen falta gestos y mensajes de ruptura para volverlos visibles. Tomamos el concepto de habitus de la reflexión de Bourdieu (1991), quien lo define como: 
[...] sistemas de disposiciones duraderas y transferibles, estructuras estructurantes, es decir, como principios generadores y organizadores de prácticas y representaciones que pueden estar objetivamente adaptadas a su fin sin suponer la búsqueda consciente de fines y el dominio expreso de las operaciones necesarias para alcanzarlos, objetivamente "reguladas" y "regulares" sin ser el producto de la obediencia a reglas, y, a la vez que todo esto, colectivamente orquestadas sin ser producto de la acción organizadora de un director de orquesta (Bourdieu, 1991: 92).

Como parte de este esfuerzo por visibilizar el sexismo, reseñamos el siguiente caso: en marzo de 2015, un grupo de alumnas pegó en los muros de la Escuela Nacional de Trabajo Social - cuyo estudiantado está compuesto mayoritariamente por mujeres - una serie de carteles en los que citaban textualmente frases que algunos de sus profesores habían emitido abiertamente en los salones de clase (Ciudadanos en Red, 2015):

Si no saben ni barrer, ¿cómo van a saber estudiar?

¡Es una lástima que las alumnas de Trabajo Social sean tan fachosas!

Para mis alumnas, que no dan una en derecho, ni en trabajo social, ni en nada... excepto...

Como ya eres la Lic. Trabajadora Social, de seguro no sabes ni hacer un arroz, ¿verdad?

Las mujeres son objetos sexuales que los hombres se compran para cogérselas a diario.

Con suerte, las mujeres que se someten a un aborto mueren en el proceso. Tienes unos dientes cachondos.

Es fácil apreciar la licencia que se otorgan a sí mismos estos docentes para expresar de manera descarada el desdén que sienten por la población femenina en general, y en particular por las estudiantes a las que directamente se les hacen estos comentarios. Así, en pleno salón de clase, hay quienes dan rienda suelta a sus sentimientos de superioridad por el hecho de pertenecer al "sexo fuerte", y exhiben el desprecio y la irritación y que les inspiran esos "otros" seres a quienes históricamente posicionan como inferiores. ¿Qué es lo que está en la base de la libertad que muestran estos profesores para expresarse de maneras tan desagradables ante sus estudiantes? ¿Qué alimenta su animadversión hacia las mujeres? ¿Qué satisfacción encuentran en el ejercicio de la discriminación? Si bien estas preguntas todavía requieren investigación seria, lo que es innegable es que el sexismo practicado en los salones de clase genera malestar, confusión y tensiones. Ilustramos estos efectos a partir del relato de una estudiante de esa misma escuela que reacciona ante los comentarios sexistas de un profesor: 
Fue tal mi impresión - porque nunca me había pasado algo similar - que me quedé pasmada, no reaccioné, lamentablemente no dije nada, pero me sentí muy ofendida, agredida y molesta. Ese día salí de muy mal humor de mi clase. Cuando lo comenté con algunas de mis compañeras, ellas compartían el malestar, pero me recomendaron no hacer nada por el miedo que todas tenemos a sufrir represalias sobre nuestra calificación. En ese momento no sabía qué hacer, solo me sentí muy mal. Lo platiqué en casa y mi hermana, que también cursó esta carrera, me comentó que a ella también le dio clase ese maestro y que en su momento se aguantó: decidió no hacer nada por las mismas razones que teníamos nosotras. ${ }^{3}$

Aunque la actitud del profesor mejora en clases subsiguientes, el enojo y desasosiego de la estudiante, y el eco que generan en sus familiares y en su tutora, la conducen a vencer el miedo a las represalias y a escribir la carta en la que vierte su denuncia y pide orientación para tramitarla:

Sé que han pasado algunos días, pero al final decidí actuar y vencer el miedo. La verdad, me siento sola y poco respaldada por mi grupo, me han hecho sentir que soy una exagerada y que sólo voy a crear problemas con esto. Me parece que eso también puede ser porque la violencia la tenemos tan naturalizada que preferimos verla como broma o algo sin importancia. Este suceso me ha generado mucho conflicto personal, debo reconocer que tengo miedo a sufrir represalias en mi calificación, por ejemplo. Pero a pesar de ello, sé que con algo se tiene que empezar y que, si esto ayuda a que no se repita y se construyen relaciones de equidad y respeto para tener un ambiente más grato y favorable en nuestras aulas, estoy dispuesta a correr el riesgo. ${ }^{4}$

El temor a las represalias que llevó a las compañeras de esta alumna a traducir su malestar en silencio, a minimizar el significado de este mensaje - su claro llamado a mantener un orden del que el docente no es sólo defensor sino también beneficiario - calificándolo como broma, da cuenta de uno de los mecanismos que permiten a profesores como éste expresar alegremente su fantasía de ser superior por el simple hecho de ser hombre.

La investigación de Barreto (2017) aborda situaciones de intimidación y de hostigamiento sexual (ocurridas entre 2011 y 2015) por parte de profesores o de estudiantes contra alumnas de las facultades de Ciencias Políticas y Sociales, Ciencias, y Filosofía y Letras, así como de la Escuela Nacional Preparatoria. Estos casos fueron denunciados públicamente mediante los medios

\footnotetext{
${ }^{3}$ Esta cita es un extracto de una carta escrita por la alumna para solicitar orientación; un análisis de este caso que se presenta en Mingo y Moreno, 2017.

${ }^{4}$ Idem.
} 
que estas mujeres tuvieron a su alcance. En la interpretación de Barreto, el paso a la denuncia pública se ve forzado por la falta de atención inmediata en las instancias responsables de resolver estos conflictos. Hay aquí, de nuevo, un movimiento de ruptura capaz de erosionar los niveles de tolerancia al sexismo que estructuran el habitus universitario.

Desde luego, apelar a la denuncia pública tiene costos para las denunciantes. El sexismo hace daño porque uno de sus resortes es la implicación de que la mujer agredida tiene parte sustantiva de la culpa. Por eso es tan común que las mujeres sean revictimizadas cuando deciden denunciar: porque un acto de acoso o de agresión sexual puede imputárseles como instigadoras. Pero, además, el ocultamiento es la forma más económica que tienen las instituciones para "mantener las aguas quietas" y salvaguardar la imagen ideal que de sí mismas han construido. El reconocimiento del sexismo en cualquiera de sus manifestaciones produce agudas resistencias en una comunidad en la que el orden de género forma parte del ADN de la institución.

Por su parte, Guevara (2003: 41) documenta cómo un director de facultad trivializa el intento de violación que vivió una estudiante. Cuando un grupo de académicas lo interrogó sobre las medidas de seguridad que se iban a tomar para impedir que una situación así se repitiera, "él respondió que en realidad a la estudiante no le había pasado nada iporque no la había violado!, y en cambio al joven que la había agredido sí lo habían dañado para toda su vida porque a él lo habían fichado en la estación de policía". Junto con la frivolización del ataque sufrido por esta alumna, salta a la vista la solidaridad que despierta en este funcionario el agresor debido al "daño" que se le ocasionó con la denuncia.

En los cinco casos estudiados por Mingo y Moreno (2015) dentro de la institución universitaria - el de una estudiante de ingeniería, una profesora de una facultad con mayoría de varones, una joven que ingresó a trabajar en el área administrativa de una sede foránea y dos de las alumnas que denunciaron públicamente el acoso de que eran objeto - , el sexismo es el hilo que hilvana experiencias tan diversas y aparentemente ajenas entre sí como: a) los insultos, amenazas, acusaciones y el acoso de un profesor hacia una alumna que decidió romper la relación sentimental que tenía con él, y b) la devaluación de la inteligencia de una futura ingeniera cuando un profesor dice en clase que va a utilizar una lavadora de ropa como ejemplo apropiado para que la única mujer del grupo entienda la explicación que él va a dar ese día. Como vemos, la elección de este ejemplo para la estudiante permite al docente, por un lado, utilizar a esta joven para mostrarse "ingenioso y simpático" frente a su alumnado masculino y, por otro, refrescar la memoria de la 
estudiante y de sus compañeros sobre el lugar de las mujeres (los quehaceres domésticos) y sus limitaciones intelectuales.

Aunque parezca mentira, la puesta en duda de la capacidad intelectual de las mujeres sigue siendo un tema recurrente en el imaginario de la Universidad. La investigación de Buquet (2013) con investigadoras de la Coordinación de la Investigación Científica de la UNAM aporta el siguiente testimonio: “Un colega dice: 'Ay, qué chistoso escuchar a dos mujeres hablando de física', y le digo: 'pues no estás en el salón de belleza, estás en el Instituto de Física, ¿por qué va a ser extraño?'"; otra investigadora, del Instituto de Ingeniería, dice: “No, aquí no hay problemas de género. De lo que me quejo es que los estudiantes prefieren a los hombres, casi no a las mujeres, me cuesta mucho trabajo conseguir estudiantes. Eso es muy serio. Me discriminan" (Buquet, 2013: 203, 211).

Un grupo focal con alumnas del Instituto de Matemáticas destapó la forma en que algunos docentes las devaluaban y la actitud paternalista que adoptaban con ellas: "nos tratan como si necesitáramos ayuda... hay los que dicen 'las mujeres, por ser mujeres, tienen un punto más'. No somos tontas, no necesitamos un punto más, no somos estúpidas ¿Por qué, por qué necesitamos un punto más? ¡Lo podemos hacer solas!”. En esa misma investigación, un grupo focal con académicas dejó ver las dudas que suscita su participación en trabajos colectivos; según las investigadoras, aunque sea en "tono de broma", siempre está presente la insinuación de que ellas reciben ayuda de sus compañeros para realizar su trabajo: "yo sí siento que los hombres no están convencidos de que el trabajo sea tuyo. Como mujer, quién sabe si tú podías solita... es sutil, se bromea al respecto". Otra investigadora afirma: "se dudaba mucho de mi independencia, y a mí me partió. Yo me decía '¿y cómo se prueba eso? Ahí está mi trabajo hecho ¿no?' Es un martirio, un problema ganarse un lugar, un reconocimiento propio" (PUEG, 2010: 53, 33 y 36).

La devaluación del trabajo de las mujeres y la puesta en duda de su capacidad intelectual florecen entre la población estudiantil: en grupos focales con estudiantes de la Facultad de Economía (Botello, 2007), los varones señalaron las limitaciones que veían en el comportamiento académico de sus compañeras en los siguientes términos:

Nosotros las conocemos como las hormiguitas, porque tienen más facilidad, primero de hacer grupos de estudio... Hormiguitas, ¡qué bonito! Forman grupitos y las ves estudiando y son muy macheteras. Yo no puedo decir que sean las personas que al momento de estar [trabajando] den la súper idea, pero sí son muy conscientes de entregar las tareas, entregar trabajos... es una ventaja que tienen ellas (Botello, 2007). 
Yo veo dos niveles, el talachero, el estar macheteando siempre con tareas... yo veo que las mujeres lo cumplen más, en general las mujeres llegan hasta el nivel talachero. Hay otro nivel más demandante en cuanto a potencial creativo... me ha tocado que muy pocas mujeres van allá, a esa clase de actividad (Botello, 2007).

Junto a la visión de estos jóvenes acerca de sus compañeras como hormiguitas hacendosas carentes de pensamiento creativo, Botello (2007) identificó que, para ellos, intervenir en clase y en voz muy alta ("para que se imponga mi frase, mi opinión") era valorado como signo de seguridad y poder. Las alusiones a las diferencias que veían en el volumen de voz utilizado por unos y otras les permitía posicionarse a sí mismos como superiores:

Mientras nosotros empezamos hablando normal, terminamos gritando, ellas empiezan bien y terminan con el volumen bajito, son como la voz del pueblo... se pierde (Botello, 2007).

Les hace falta más fuerza, les falta decir "no quiero ser del montón". En lugar de seguir debatiendo, bajan el tono de voz y se rinden (Botello, 2007).

La cultura de supremacía varonil se reproduce en todo el campus universitario mediante mecanismos como el de la objetualización de las mujeres. En un grupo focal realizado con alumnos de la Facultad de Derecho (Agoff y Mingo, 2010), se describió la práctica de clasificar a las estudiantes en razón de sus atributos físicos. Esta cultura de pares reivindica tal recurso a partir de la valorización de las mujeres como cuerpos para "admirar" o "despreciar", para "conquistar" o "ignorar", y las imágenes que se construyen en ese contexto les sirven como medios de comunicación para posicionarse en una escala de dominación que establece los rangos de la masculinidad hegemónica: aquellos que pueden conquistar a las mujeres más hermosas se miran con complacencia en el espejo del "macho Alfa".

Otro mecanismo de reproducción de una cultura que sigue considerando a las mujeres "intrusas en la universidad" es el alboroto de chiflidos y gritos con que los alumnos "saludan" el paso de las mujeres por el patio de la Facultad de Ingeniería. Lejos de censurar estas conductas, en un grupo focal realizado por Cerva (2011), varios profesores las consideran una tradición valiosa y les restan gravedad, sin detenerse en la consecuencia obvia de que cualquier mujer que pretenda transitar por esta facultad se ve obligada a buscar otras rutas para evitar ese espacio, o a modificar su comportamiento y su forma de vestir en un intento por pasar inadvertida. 
El carácter sistémico del sexismo dentro de la UNAM se aprecia con mayor claridad en los datos obtenidos en una encuesta aplicada por Buquet et al. (2014) a muestras representativas de cada una de las poblaciones - estudiantes, personal académico y personal administrativo - que desarrollan su quehacer en Ciudad Universitaria. Entre las evidencias de la devaluación de las capacidades femeninas está el hecho de que 53.2\% de las mujeres y 55.1\% de los hombres de la población académica entrevistada afirman que han escuchado por lo menos una vez un comentario semejante a "¿Qué puedes esperar?, es una mujer". En la población estudiantil, casi $40 \%$ señaló que las respuestas y opiniones de las alumnas no son tomadas con la misma seriedad que se da a las de sus compañeros de aula. Los datos obtenidos en la población administrativa muestran que $67.8 \%$ de las mujeres y $53.1 \%$ de los hombres habían escuchado en una o más ocasiones afirmaciones como "a menudo las mujeres logran puestos, premios y promociones porque seducen a los hombres poderosos".

\section{Conclusiones}

Casi mil años después de la aparición de la cultura monacal como un mundo sin mujeres, las instituciones de educación superior deben reconsiderar sus disposiciones, actitudes y prejuicios con seriedad. El desafortunado chiste de Tim Hunt tiene eficacia real porque verbaliza una idea que está latente en los ambientes universitarios: las mujeres metemos el cuerpo en la universidad, rompemos con el ideal de un pensamiento descarnado, objetivo, capaz de funcionar al margen de las necesidades corporales; y además, introducimos el desorden del deseo, la sexualidad, la sensualidad. El reclamo de un territorio exclusivo para la producción del conocimiento que no se vea entorpecido por el escándalo de la vida cotidiana es uno de los subtextos en la reproducción de los mecanismos de exclusión que garantizan la supremacía masculina.

De esta forma se construye un mundo imaginario donde privan diferencias insalvables y jerarquizadoras a partir de las cuales se rigen todas las relaciones sociales desde un lugar naturalizado e incorporado: el del habitus. Esta estructura latente y soterrada de las interacciones exige permanentemente la imposición de un orden que nunca termina por establecerse de manera definitiva porque las mujeres insisten en participar de la vida social más allá del ámbito de la familia.

Por eso se vuelve tan problemática la presencia femenina en el ámbito público en general, y en el espacio universitario en particular: porque rom- 
pe con la ficción acariciadora de la supremacía varonil. De ahí surgen las constantes llamadas al orden que observamos en los diferentes escenarios descritos. Las reacciones de malestar, de rechazo, de arrogancia y de enojo son otras tantas reivindicaciones del posicionamiento de supremacía que los varones reclaman para sí en todos los espacios de la vida en sociedad.

Sólo así adquieren sentido las apreciaciones del doctor Hunt: las mujeres producen un desestabilizador alboroto en los laboratorios, en las aulas, en los auditorios, en los cubículos, y nos recuerdan que, además de la mente intachable, objetiva e imperturbable del sabio, existe un mundo complejo, desordenado, proclive al deseo y lleno de tensión donde no se puede ya pensar con la tranquilidad y el sosiego que produce la cálida celda del célibe monje medieval.

\section{Referencias}

Agoff, Carolina y Araceli, Mingo (2010). Tras las huellas de género. Vida cotidiana en tres facultades, México, Programa Universitario de Estudios de Género, documento mimeografiado.

Alic, Margaret (1991). El legado de Hipatia. Historia de las mujeres en la ciencia desde la Antigüedad hasta fines del siglo XIx. México: Siglo XXI.

Barreto, Magali (2017). Violencia de género y denuncia pública en la Universidad. Revista Mexicana de Sociología, vol. 79, núm. 2 (abril-junio), pp. 261-286.

Bosch Fiol, Esperanza, Victoria A. Ferrer Pérez y Margarita Gili Planas (1999). Historia de la misoginia. Barcelona: Universitat de les Illes Balears / Anthropos.

Botello, Luis (2007). Clima organizacional en la Facultad de Economía desde una perspectiva de género: reporte de estudio cualitativo. México: Programa Universitario de Estudios de Género-UnAM, documento mimeografiado.

Bourdieu, Pierre (1991). El sentido práctico. Madrid: Taurus Humanidades.

Brown, Peter (1988). The Body and Society. Men, Women, and Sexual Renunciation in Early Christianity. Nueva York: Columbia University Press.

Buquet, Ana (2013). Sesgos de género en las trayectorias académicas universitarias: orden cultural y estructura social en la división sexual del trabajo. Tesis de doctorado en Ciencias Políticas y Sociales con orientación en Sociología. México: Posgrado de Ciencias Políticas y Sociales, Universidad Nacional Autónoma de México.

Buquet, Ana, Jennifer Cooper, Araceli Mingo y Hortensia Moreno (2014). Intrusas en la universidad. México: Universidad Nacional Autónoma de México. Disponible en http://www.iisue.unam.mx/libros/?dd-product=intrusas-en-launiversidad-2 [consulta: 22 de septiembre de 2015].

Caplan, Paula J., Mary Crawford, Janet Shibley Hyde y John T. E. Richardson (1997). Gender Differences in Human Cognition. Nueva York y Oxford: Oxford University Press. 
Cerva, Daniela (2011). Informe de investigación: resultado de los grupos focales realizados a la población académica y población administrativa de la Facultad de Psicología, Facultad de Derecho y Facultad de Ingeniería de la Universidad Nacional Autónoma de México. Documento mimeografiado.

Ciudadanos en Red (2015). Alumnas de la UNAM denuncian machismo de profesores. Recuperado el 1 de septiembre de 2017 de http:/ / ciudadanosenred.com. $\mathrm{mx} /$ alumnas-de-la-unam-denuncian-machismo-de-profesores/; y de http:/ / www.mtsmexico.org/Denuncian-machismo-en-la-Escuela-Nacional-de

Commo McLaughlin, Eleanor (1974). Equality of Souls, Inequality of Sexes: Woman in Medieval Theology. En Rosemary Radford Ruether (comp.), Religion and sexism / Images of Woman in the Jewish and Christian Traditions. Nueva York: Simon and Schuster, pp. 222-257.

Épiney-Burgard, Georgette, y Emilie Zum Brunn (1998). Mujeres trovadoras de Dios / Una tradición silenciada de la Europa medieval. Barcelona: Paidós.

Fausto-Sterling, Anne (1992). Myths of Gender / Biological Theories about Women and Men. Nueva York: Basic Books.

Fine, Cordelia (2010). Delusions of Gender / The Real Science Behind Sex Differences. Londres: Icon Books.

Guevara, Elsa (2003). Ser académica en la FEs-Zaragoza. Género y evaluación. En Olga Bustos y Norma Blazquez (coords.), Qué dicen las académicas acerca de la UNAM, México, Colegio de Académicas Universitarias, pp. 139-149.

Han, Byung-Chul (2014). Psicopolítica. Barcelona: Herder.

Holland, Jack (2010). Una breve historia de la misoginia / El prejuicio más antiguo del mundo. México: Océano.

Hunt, Tim (2015). Discurso ante The World Conference of Science Journalists (wCSJ), el 9 de junio. Recuperado el 9 de septiembre de 2015 de https:// en.wikipedia.org/wiki/Tim_Hunt\#Career

Laqueur, Thomas (1994). La construcción del sexo. Cuerpo y género desde los griegos hasta Freud. Madrid: Ediciones Cátedra/Universitat de València/Instituto de la Mujer.

McKie, Robin (2015). Shamed Nobel laureate Tim Hunt 'ruined by rush to judgment after stupid remarks'. Recuperado el 11 de septiembre de 2015 de http:/ / www.theguardian.com/science/2015/jun/13/tim-hunt-forced-to-resign

Meikle, James (2015). Dimbleby resigns from UCL in protest at 'disgraceful' treatment of Sir Tim Hunt. Recuperado el 11 de septiembre de 2015 de http:/ / www.theguardian.com/education/2015/jun/30/jonathan-dimbleby-resigns-ucl-sir-tim-hunt

Mingo, Araceli y Hortensia Moreno (2015). El ocioso intento de tapar el sol con un dedo: violencia de género en la universidad. Perfiles Educativos, vol. xxxvII, núm. 148, pp. 138-155, http://www.iisue.unam.mx/perfiles/index. php?numero=148\&anio=2015 [consulta: octubre 9, 2015].

Mingo, Araceli y Hortensia Moreno (2017). Sexismo en la universidad. Estudios Sociológicos, vol. xxxv, núm. 105, septiembre-diciembre, 571-595.

Noble, David F. (1993). A World without Women / The Christian Clerical Culture of Western Science. Nueva York: Alfred A. Knopf. [versión Kindle] 
Palermo, Alicia Itatí (2006). El acceso de las mujeres a la educación universitaria. Revista Argentina de Sociología, vol. 4, núm. 7 (jul./dic.), pp. 11-46.

PUEG (2010). Diagnóstico de la situación de mujeres y hombres por dependencia. Instituto de Matemáticas UNAM, apoyado con financiamiento de Conacyt. Informe Técnico, disponible en línea: http:/ / www.matem.unam.mx/acerca-de/noticias/ diagnostico-pueg-3a-parte [consulta: 10 de agosto de 2015].

RAE, Diccionario de la lengua española. Recuperado de http://dle.rae. es/?id=PP4dmnK el 6 de marzo de 2018.

Sánchez Mora, Ana María (2004). La ciencia y el sexo. México: Dirección General de Divulgación de la Ciencia de la unAm.

Schiebinger, Londa (2004). ¿Tiene sexo la mente? Las mujeres en los orígenes de la ciencia moderna. Madrid: Cátedra.

Tazi, Nadia (1989). Celestial Bodies: A Few Stops on the Way of Heaven. En Michel Feher, Ramona Naddaff y Nadia Tazi (comps.), Fragments for a History of the Human Body, parte dos. Nueva York: Zone, pp. 519-552.

The Royal Society (2015). Science needs women. Recuperado el 9 de septiembre de 2015 de https:/ / royalsociety.org/news/2015/06/tim-hunt-comments /

Twitter, @twittermedia (s/f). Distractingly sexy. Recuperado el 14 de septiembre de 2015 de https://twitter.com/twittermedia/timelines/609133276981129216.

Universidad Nacional Autónoma de México, unam (s/d). Acerca de la unAm. Recuperado el 5 de marzo de 2018 de https://www.unam.mx/acerca-de-launam

Universidad Nacional Autónoma de México, unAm (2017). Agenda 2017. Recuperado el 5 de marzo de 2018 de http://agendas.planeacion.unam.mx/pdf/ Agenda-2017.pdf

Wikipedia (s/f), Tim Hunt. Recuperado 9 de septiembre de 2015 de https:/ / en.wikipedia.org/wiki/Tim_Hunt\#Career

WISE (2015). "Must do better": End of term report on UK's progress attracting women into science. Recuperado el 17 de septiembre de 2015 de https:/ / www. wisecampaign.org.uk/news/2015/07/must-do-better-end-of-term-reporton-uks-progress-attracting-women-into-science

Youtube (s/f). Nobel Scientist Tim Hunt Sparks A Distractingly Sexy Campaign. Recuperado el 14 de septiembre de 2015 de https://www.youtube.com/ watch? $\mathrm{v}=007 \mathrm{ome} 2 \mathrm{Y} 7 \mathrm{fU}$ 